\title{
Analysis and Measurement of Neck Loads
}

\author{
Sean P. Moroney, Albert B. Schultz, and James A. A. Miller \\ Department of Mechanical Engineering, University of Michigan, Ann Arbor, Michigan, U.S.A.
}

\begin{abstract}
Summary: To examine the loads imposed on the structures of the neck by the performance of physical tasks, a biomechanical model of the neck was constructed. The model incorporated 14 bilateral pairs of muscle equivalents crossing the $\mathrm{C} 4$ level. A double linear programming optimization scheme that minimized maximum muscle contraction intensity and then vertebral compression force while equilibrating external loads was used to calculate the muscle contraction forces required and the motion segment reactions produced by task performance. To test model validity, 14 healthy adult subjects performed a series of isometric tasks requiring use of their neck muscles. These tasks included exertions in attempted flexion, extension, and left and right lateral bending and twisting. Subjects exerted maximum and submaximum voluntary efforts. During the performance, surface myoelectric activities were recorded at eight locations around the periphery of the neck at the $\mathrm{C} 4$ level. Calculated forces and measured myoelectric activities were then linearly correlated. Mean measured voluntary neck strengths in 10 male subjects were as large as $29.7 \mathrm{Nm}$. Four female subjects developed mean strengths that were approximately $60 \%-90 \%$ of those of the males. In both sexes, neck muscle strengths were approximately one order of magnitude lower than previously measured lumbar trunk strengths. Mean calculated neck muscle contraction forces ranged to $180 \mathrm{~N}$. Mean calculated compression forces on the C4-5 motion segment ranged to $1164 \mathrm{~N}$, lateral shear forces ranged to $125 \mathrm{~N}$, and anteroposterior shear forces ranged to $135 \mathrm{~N}$. Correlation coefficients between the calculated muscle forces and the measured myoelectric activities were as large as 0.85 in some muscles, but generally were smaller than this. Key Words: Neck biomechanics - Spine biomechanics-Biomechanical models - Myoelectric measurements.
\end{abstract}

The neck is susceptible to trauma and is frequently a site of pain $(7,11,15)$. Episodes of neck pain have been estimated to affect at one time or another approximately $40 \%$ of the population $(6,8,9)$. The pathogenesis of neck pain is often unknown, but evidence suggests that mechanical factors may sometimes be involved. For example, Kelsey et al. (10) found a marked increase in risk for cervical disc prolapse in association with frequent diving from a board (odds ratio of 2.3 , for

Address correspondence and reprint requests to Albert $B$. Schultz at University of Michigan, Ann Arbor, MI 48109-2125, U.S.A. those diving 10 times or more in the past 2 years). Thus, the determination of the magnitudes of neck muscle contraction forces and of cervical spine compression and shear forces imposed by the performance of physical tasks is likely to have clinical relevance.

Loads internal to the lumbar trunk and spine have been studied (1,16-18). In those and similar studies, internal loads were calculated using biomechanical model analyses and model validity tested through measurement of trunk muscle myoelectric activities. Calculations and measurements generally were highly correlated.

The present study applied these techniques to the 
cervical spine and its musculature. Fourteen subjects performed 30 isometric tasks calling for neck muscle contractions. These tasks included attempted neck flexion, extension, and left and right lateral bending and twisting. Biomechanical model analyses of these efforts were used to predict the required neck muscle contraction forces and measurements of the neck muscle myoelectric activity were used to test the validity of the predictions. A primary aim of this study was to examine quantitatively what loads arise internal to the neck when external loads are applied to the head. A secondary aim was to measure maximum voluntary strengths of the neck musculature.

\section{Experimental Measurements}

Fourteen adult volunteers, ten males and four females, participated in the experiments. Data on the subjects are presented in Table 1 . None of the subjects reported a history of neck injury or notable neck pain.

Each subject performed 30 quasistatic tasks calling on his neck musculature. The subjects were asked to sit in a chair placed in a reference frame. Their shoulders were strapped to a board fixed behind the chair, and their hands placed in their laps. A $2.5 \mathrm{~kg}$ helment was worn by each subject. The helment was equipped with attachments to permit application of external loads. The helment could be custom-fitted by means of foam inserts. The subjects wore a bathing cap to maximize friction between head and helment. The $\mathrm{C} 4$ level of the neck was located by palpation of the vertebrae. Markers were placed on the side of the neck to indicate the
TABLE 1. Subject anthropometric data

\begin{tabular}{|c|c|c|c|c|c|c|}
\hline \multirow[b]{2}{*}{ Subject } & \multirow[b]{2}{*}{ Sex } & \multirow[b]{2}{*}{$\begin{array}{c}\text { Age } \\
\text { (years) }\end{array}$} & \multirow[b]{2}{*}{$\begin{array}{l}\text { Height } \\
(\mathrm{cm})\end{array}$} & \multirow[b]{2}{*}{$\begin{array}{l}\text { Weight } \\
\text { (N) }\end{array}$} & \multicolumn{2}{|c|}{ Neck diameters } \\
\hline & & & & & $\begin{array}{l}\text { A-P } \\
\text { (cm) }\end{array}$ & $\begin{array}{l}\text { Lat. } \\
(\mathrm{cm})\end{array}$ \\
\hline 1 & $M$ & 43 & 183 & 758 & 10.7 & 11.4 \\
\hline 2 & $\hat{M}$ & 59 & 173 & 602 & 11.4 & 11.7 \\
\hline 3 & M & 21 & 175 & 557 & 10.0 & 11.0 \\
\hline 4 & $\mathrm{M}$ & 25 & 183 & 803 & 12.1 & 11.4 \\
\hline 5 & M & 24 & 175 & 776 & 12.1 & 11.4 \\
\hline 6 & M & 28 & 173 & 647 & 11.1 & 11.1 \\
\hline 7 & M & 33 & 168 & 713 & 11.5 & 11.5 \\
\hline 8 & M & 29 & 173 & 638 & 10.4 & 10.5 \\
\hline 9 & M & 19 & 170 & 535 & 10.8 & 11.2 \\
\hline 10 & M & 25 & 198 & 869 & 11.2 & 10.2 \\
\hline 11 & $\mathrm{~F}$ & 34 & 160 & 508 & 9.3 & 8.5 \\
\hline 12 & $\mathrm{~F}$ & 27 & 173 & 580 & 9.3 & 9.3 \\
\hline 13 & $\mathrm{~F}$ & 23 & 168 & 513 & 8.8 & 8.8 \\
\hline 14 & $\mathrm{~F}$ & 20 & 155 & 473 & 8.3 & 8.9 \\
\hline Means & M & 30.6 & 177.0 & 689.8 & 11.1 & 11.1 \\
\hline $\mathrm{SD}$ & M & 12.1 & 8.9 & 111.5 & 0.7 & 0.5 \\
\hline Means & F & 26.0 & 163.8 & 518.6 & 8.9 & 8.9 \\
\hline SD & $F$ & 6.1 & 7.9 & 44.6 & 0.5 & 0.3 \\
\hline
\end{tabular}

level of $\mathrm{C} 4$, and on the helment to indicate the approximate center of mass of the head plus helment. The coordinates of these points were recorded during testing by using a horizontal and a vertical scale along with a plumb bob and a level.

In one series of tasks, each subject was asked first to relax and then, with head and neck maintained in an upright posture, to exert for $5 \mathrm{~s}$ his maximum voluntary strength against a load cell in attempted flexion, extension, and left and right lateral bending and twisting (Fig. 1). Given feedback, he then exerted $25 \%$ and $50 \%$ of his maximum strength in a like manner. In another series of tests, the subjects were asked to resist applied moments in flexion, extension, and left and right lateral bending and twisting. These moments were pro-
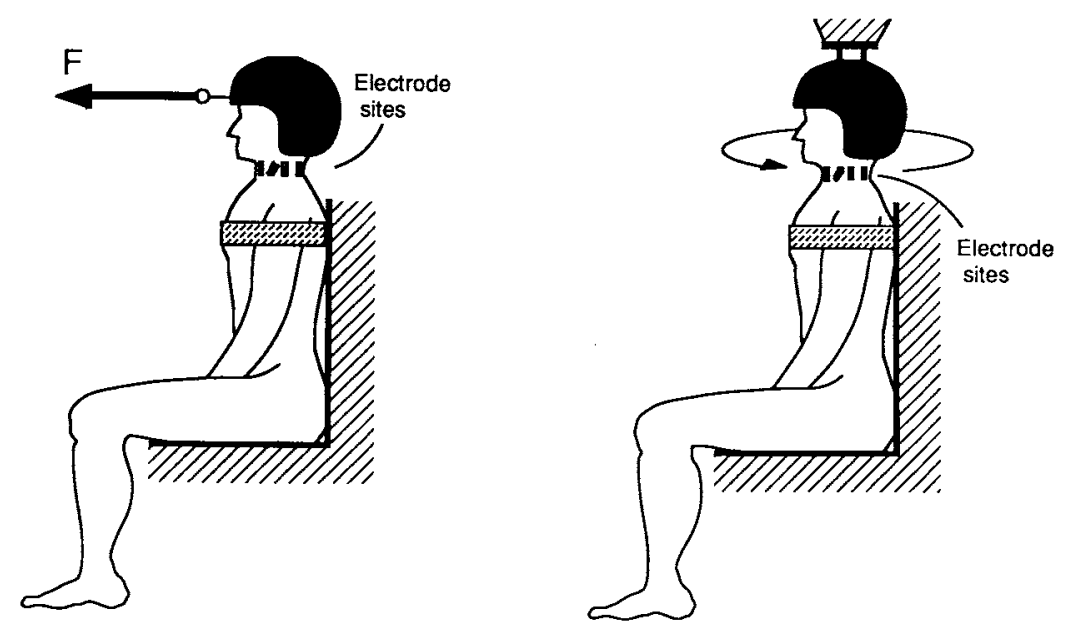

FIG. 1. Schematic of testing procedures. The seated subject has his trunk restrained and electrodes mounted on his neck at the C4 level. (Left) The subject resists the flexion moment created by an anteriorly directed force. (Right) The subjeci attempts to twist his neck to the left. 
duced by free-hanging weights using cords attached to hooks on the helment and pulleys. The moments applied were approximately $10 \%$ and $30 \%$ of the maximum strengths. The maximum duration of the tasks was $10 \mathrm{~s}$. The subjects rested for at least 2 min between tasks; a 10 -min rest period was provided between sets of tasks (Table 2).

Eight bipolar electrodes were affixed to the surface of the neck at the $\mathrm{C} 4$ level at bilaterally symmetric locations. The electrode locations, denoted as (1) anterior, (2) anterolateral, (3) posterolateral, and (4) posterior, with approximate azimuth angles of $35^{\circ}, 70^{\circ}, 105^{\circ}$, and $150^{\circ}$, respectively, were determined by reference to topographical landmarks. These locations were (a) midway between the anterior midline and the anterior border of the sternocleidomastoid (SCM) muscle, (b) midway between the anterior and posterior borders of the SCM

TABLE 2. Sequence of tasks performed

\begin{tabular}{ll}
\hline Attempted movements & $\begin{array}{c}\text { Percent of } \\
\text { max. vol. effort }\end{array}$ \\
\hline Attempted movements & \\
1 Left twist & 100 \\
2 Left twist & 25 \\
3 Left twist & 50 \\
4 Right twist & 100 \\
5 Right twist & 25 \\
6 Right twist & 50 \\
Resisted loads & \\
7 Right twist & 10 \\
8 Right twist & 30 \\
9 Left twist & 10 \\
10 Left twist & 30 \\
Attempted movements & \\
11 Extension & 100 \\
12 Extension & 25 \\
13 Extension & 50 \\
14 Left bending & 100 \\
15 Left bending & 25 \\
16 Left bending & 50 \\
17 Flexion & 100 \\
18 Flexion & 25 \\
19 Flexion & 50 \\
20 Right bending & 100 \\
21 Right bending & 25 \\
22 Right bending & 50 \\
Resisted loads & \\
23 Flexion & 10 \\
24 Flexion & 30 \\
25 Right bending & 10 \\
26 Right bending & 30 \\
27 Extension & 10 \\
28 Extension & 10 \\
29 Left bending & 30 \\
30 Left bending & \\
\hline
\end{tabular}

In the resist tasks, the loads applied were determined from the loads developed in the maximum effort tasks. muscle, (c) midway between the posterior border of the SCM muscle and the anterior border of the upper trapezius muscle, and (d) midway between the anterior border of the upper trapezius muscle and the posterior midline. The myoelectric signals were preamplified, then further amplified, full-wave rectified, integrated with a reset time constant of $0.2 \mathrm{~s}$ (using Grass Instrument Company Model 7P3 myoelectric signal processors), and displayed on an eight-channel chart recorder. Mean signal levels were determined from these recordings.

\section{BIOMECHANICAL MODEL ANALYSES}

The contraction forces in the neck muscles and the compression and shear loads they imposed on the cervical spine were computed for each task and each subject by biomechanical analyses. Each analysis was based on the requirement that the structures superior to an imaginary cutting plane at the $\mathrm{C} 4$ level remain in equilibrium during the performance. The analysis was carried out in two steps. First, the net reaction needed to equilibrate the structures superior to the $\mathrm{C} 4$ level was computed. Then, a set of neck muscle contraction forces that could produce that net reaction and its resulting set of compression and shear loads on the C4-5 motion segment was calculated.

Knowledge of the external loads and of the weights of the subjects' heads and the helment was required for the computations. The external loads were the known cord-applied forces and moments. The weight of the head was assumed to be $7.3 \%$ of the subject's total body weight and to act midway between the ears, based on the data of Clauser et al. (3). The coordinates of the force application points were available for each task and for each subject from measured configuration data. These data were entered into the six equations expressing the requirements for equilibrium. These were that the applied and body segment weight forces had to be balanced by the forces transmitted across the $\mathrm{C} 4$ section along the left, posterior, and superior axes; and the moments of those forces had to be balanced by the three moments about those $\mathrm{C} 4$ section axes. These requirements enabled the six components of the net reaction transmitted across the $\mathrm{C} 4$ section to be computed. The contraction forces in 14 pairs of neck muscles and the cervical spine compression and shear loads were then calculated from the net reaction using a biomechanical model of the $\mathrm{C} 4$ cross section and solving the model equations by an optimization technique.

A scaled cross-sectional anatomy drawing of the 
C4 level the carefully detailed drawings of Eycleshymer and Schoemaker (4) were used, although data from more modern texts could have served as well] provided the basic data on muscle centroid locations and cross-sectional areas (Fig. 2). A reproduction of the drawing was pasted onto a uniform sheet of cardboard. By weighing cutouts of each muscle cross section, and weighing the total rectangular cross section defined by the neck diameters, the relative area of the cross section of each muscle was determined. Cutout centroids were located by constructing cross plumb lines on the cutouts. Centroid locations relative to neck diameters were then determined by linear scaling. Muscle lines of action were determined similarly from scaled cross-sectional drawings at adjacent levels.

To construct the model, the origin of an orthogonal coordinate system was placed at the $\mathrm{C} 4-5$ disc center, with axes positive to the left, posterior, and superior. Muscle centroidal coordinates were expressed relative to the frontal and sagittal plane neck diameters; their areas were scaled relative to the product of the diameters (Table 3). The muscle forces were assumed to act at the muscle centroids.

In the model, the $\mathrm{C} 4-5$ motion segment was assumed to offer resistance to compression and shear forces, but not to bending or twisting moments.

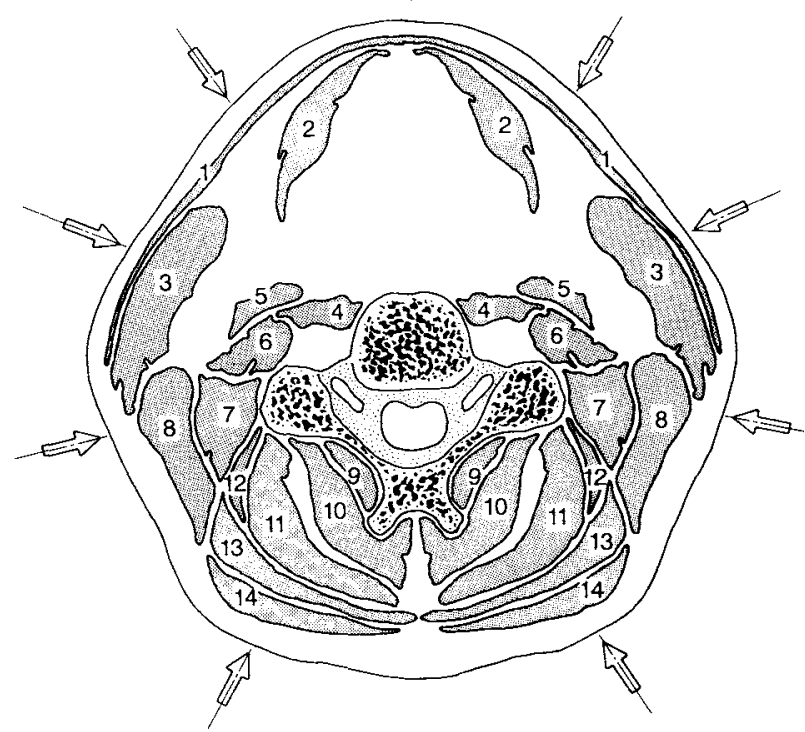

FIG. 2. A cross section of the neck at the level of the C4 illustrating the muscles modeled: (1) platysma, (2) infrahyoid, (3) sternocleidomastoid, (4) longus colli \& cervicis, (5) scalene anterior, (6) scalene medius, (7) longissimus cervicis, (8) levator scapulae, (9) multifidus, (10) semispinalis cervicis, (11) semispinalis capitis, (12) spenius cervicis, (13) spenius capitis, and (14) trapezius. The arrows indicate the electrode locations
This assumption, analogous to that used in the lumbar trunk model of Schultz et al. (17), was based on the data of Moroney et al. (14). They found cervical spine motion segments to have shear stiffnesses on the order of $100 \mathrm{~N} / \mathrm{mm}$ and compression stiffnesses on the order of $1000 \mathrm{~N} / \mathrm{mm}$. Thus, sizable forces could be resisted by the cervical spine with only a few $\mathrm{mm}$ of vertebral relative displacement. On the other hand, they rotational stiffnesses to be on the order of $1 \mathrm{Nm} / \mathrm{deg}$. In tasks analyzed here, the neck was maintained upright, so the motion segments probably developed rotational resistances of less than $1 \mathrm{Nm}$. The mean external moments in the tasks studied here were as large as $26 \mathrm{Nm}$. So, the assumption used seems reasonable.

The optimization scheme employed (2) first determined by linear programming the minimum muscle contraction intensity needed to equilibrate the applied load. Next, with this contraction intensity as an upper bound, the muscle equivalent forces that maintained equilibrium while minimizing the compression force on the spine were calculated, again by linear programming. This scheme called on nearly every muscle that could contribute to an activity to do so at nearly equal contraction intensities, while keeping antagonistic muscle activity to a minimum.

The predicted force in each muscle equivalent was paired with the myoelectric signal level in the electrode nearest to that equivalent. The 30 sets, one per task, of data pairs of mean measured myoelectric signal level and mean predicted contraction force were correlated by a linear leastsquares regression and the correlation coefficients computed.

\section{RESULTS}

The mean voluntary moments developed by the subjects ranged to $25.9 \mathrm{Nm}$ (Table 4).

In relaxed upright postures, mean myoelectric signals were approximately $10 \mu \mathrm{V}$ (Table 4). The largest mean signals (approximately $208 \mu \mathrm{V}$ ) were recorded from the anterior electrodes during maximal flexion. The largest mean posterior electrode signals were approximately $50 \mu \mathrm{V}$ and these occurred in maximal extension. The largest myoelectric signals during twisting or lateral bending were recorded from the anterolateral electrodes.

During attempted lateral bending, signal strengths were larger to the side of bending. In attempted twisting, the largest signals were recorded 
TABLE 3. Data incorporated into the C4 cross-section model

\begin{tabular}{|c|c|c|c|c|c|c|}
\hline \multirow{2}{*}{$\begin{array}{l}\text { Muscles } \\
\text { modeled }\end{array}$} & \multirow[b]{2}{*}{ Area } & \multicolumn{2}{|c|}{$\begin{array}{l}\text { Centroid locations } \\
\text { (left side) }\end{array}$} & \multicolumn{3}{|c|}{$\begin{array}{l}\text { Direction Angles of the } \\
\text { line of action } \\
\text { (left side) }\end{array}$} \\
\hline & & Left & Posterior & Left & Posterior & Superior \\
\hline Platysma & 0.0040 & 0.208 & -0.353 & 115 & 105 & 30 \\
\hline Infrahyoid & 0.0128 & 0.135 & -0.343 & 90 & 90 & 0 \\
\hline Sternocleidomastoid & 0.0301 & 0.396 & -0.088 & 75 & 58 & 37 \\
\hline Longus colli and cerv. & 0.0055 & 0.115 & -0.049 & 80 & 90 & 10 \\
\hline Scalene anterior & 0.0075 & 0.228 & -0.049 & 105 & 90 & 15 \\
\hline Scalene medius & 0.0079 & 0.240 & 0.010 & 105 & 103 & 20 \\
\hline Longissimus cerv. & 0.0051 & 0.260 & 0.108 & 80 & 90 & 10 \\
\hline Levator scapulae & 0.0228 & 0.323 & 0.147 & 110 & 90 & 20 \\
\hline Multifidus & 0.0083 & 0.073 & 0.176 & 140 & 70 & 45 \\
\hline Semispinalis cerv. & 0.0189 & 0.073 & 0.275 & 95 & 90 & 5 \\
\hline Semispinalis cap. & 0.0248 & 0.188 & 0.284 & 90 & 90 & 0 \\
\hline Splenius cervicis & 0.0030 & 0.260 & 0.225 & 80 & 100 & 15 \\
\hline Splenius capitis & 0.0120 & 0.250 & 0.304 & 77 & 105 & 20 \\
\hline Trapezius & 0.0144 & 0.188 & 0.373 & 120 & 90 & 30 \\
\hline
\end{tabular}

Centroid locations are given in ratio to neck frontal plane and sagittal plane diameters. Areas are given in ratio to the product of these two diameters.

from the anterior and anterolateral electrodes on the side opposite the direction of twisting. Bilateral symmetry in response to the symmetric loads was evident in the myoelectric signal increases recorded by both the posterolateral and posterior electrode pairs. The measured myoelectric signals and the predicted muscle contraction forces showed coefficients of variation that ranged generally from $25 \%$ to $75 \%$.

The largest predicted muscle contraction forces (Table 5) occurred in the SCM in maximum twisting attempts. The SCM was also the site of the largest predicted contraction forces in other maximum voluntary strength exercises, except in attempted extension. Generally, predicted muscle forces increased monotonically with increasing load. However, in a few cases, a decrease in predicted force with increasing load was observed. This occurred in those submaximal exercises for which the moment due to head and helmet weights equaled or exceeded the applied moment.

The percentage contributions of each muscle equivalent to an exertion varied. Some muscle equivalents, splenius capitis for example, contributed to all performances at nearly the same percent level. In contrast, others contributed significantly only to some types of exertions. For example. levator scapulae contributed strongly to lateral bending but negligibly to twisting. SCM was the largest single contributor to both attempted lateral bending and twisting. The infrahyoids made the largest contribution to attempted flexion. The semispinales muscles accounted for over one-half the effort in attempted extension.

The mean predicted motion segment reactions for the maximum voluntary exertions are summarized in Table 6. The largest lateral shear (approximately $125 \mathrm{~N}$ ) occurred during lateral bending. The largest anteroposterior shear (approximately $135 \mathrm{~N}$ ) occurred in extension. The largest compression (approximately $1164 \mathrm{~N}$ ) occurred during extension and the smallest (approximately $578 \mathrm{~N}$ ) during flexion. For comparison, the estimated mean weight of the subjects' heads was $46.7 \mathrm{~N}$. Thus, the calculated motion segment compression forces in the maximum exertions were 12.4 and 24.9 times head weight in attempted extension and flexion, respectively, and the shear forces were 2.7 and 2.9 times head weight in attempted lateral bending and extension, respectively.

The coefficients of linear correlation between predicted forces and measured myoelectric signal levels over all 30 tasks (Table 7) ranged from 0.29 to 0.85 . Those for the anterior and anterolateral muscles were generally high, while those for the posterolateral and posterior muscles were more variable.

Complete tabulations of results are available from the authors.

\section{DISCUSSION}

More detailed information on the present study is provided by Moroney (13). The decision to model 
TABLE 4. Mean applied moments and mean myoelectric signal levels

\begin{tabular}{|c|c|c|c|c|c|}
\hline \multirow[b]{2}{*}{ Task } & \multirow{2}{*}{$\begin{array}{l}\text { Mean } \\
\text { applied } \\
\text { moment } \\
(\mathrm{Nm})\end{array}$} & \multicolumn{4}{|c|}{ Mean left side myoelectric signal level $(\mu \mathrm{V})$} \\
\hline & & Anterior & Anterolateral & Posterolateral & Posterior \\
\hline Relaxed upright & & $12(8)$ & $10(3)$ & $11(2)$ & $5(3)$ \\
\hline $\begin{array}{l}\text { Resisted right twist, } 30 \% \\
\text { Attempted left twist, } 50 \% \\
\text { Attempted left twist, } 100 \%\end{array}$ & $\begin{array}{l}4.1(2.8) \\
4.6(1.5) \\
8.5(3.1)\end{array}$ & $\begin{array}{l}45(49) \\
35(18) \\
99(58)\end{array}$ & $\begin{array}{c}55(64) \\
57(73) \\
134(102)\end{array}$ & $\begin{array}{l}30(22) \\
34(29) \\
77(58)\end{array}$ & $\begin{array}{l}25(21) \\
34(27) \\
58(39)\end{array}$ \\
\hline $\begin{array}{l}\text { Resisted right bend, } 30 \% \\
\text { Attempted left bend, } 50 \% \\
\text { Attempted left bend, } 100 \%\end{array}$ & $\begin{array}{r}4.8(2.9) \\
6.4(3.9) \\
12.8(7.3)\end{array}$ & $\begin{array}{r}28(19) \\
31(24) \\
104(60)\end{array}$ & $\begin{array}{r}50(42) \\
47(33) \\
122(70)\end{array}$ & $\begin{array}{r}51(44) \\
46(33) \\
112(68)\end{array}$ & $\begin{array}{l}19(19) \\
18(13) \\
50(46)\end{array}$ \\
\hline $\begin{array}{l}\text { Resisted flexion, } 30 \% \\
\text { Attempted extension, } 50 \% \\
\text { Attempted extension, } 100 \%\end{array}$ & $\begin{array}{l}8.7(4.6) \\
12.6(6.6) \\
25.9(13.4)\end{array}$ & $\begin{array}{l}16(13) \\
12(2) \\
16(6)\end{array}$ & $\begin{array}{l}11(2) \\
11(4) \\
14(3)\end{array}$ & $\begin{array}{l}17(11) \\
19(16) \\
44(55)\end{array}$ & $\begin{array}{l}17(16) \\
19(9) \\
52(28)\end{array}$ \\
\hline $\begin{array}{l}\text { Resisted extension, } 30 \% \\
\text { Attempted flexion, } 50 \% \\
\text { Attempted flexion, } 100 \% \\
\end{array}$ & $\begin{array}{r}3.6(2.3) \\
5.3(3.2) \\
10.4(6.3)\end{array}$ & $\begin{array}{r}86(54) \\
99(61) \\
207(70) \\
\end{array}$ & $\begin{array}{r}90(80) \\
76(40) \\
165(71)\end{array}$ & $\begin{array}{r}35(23) \\
35(20) \\
103(54)\end{array}$ & $\begin{array}{c}14(19) \\
9(9) \\
36(37)\end{array}$ \\
\hline & & \multicolumn{4}{|c|}{ Mean right side myoelectric signal level $(\mu \mathrm{V})$} \\
\hline Task & & Anterior & Anterolateral & Posterolateral & Posterior \\
\hline Relaxed upright & & $12(2)$ & $11(1)$ & $10(2)$ & $10(1)$ \\
\hline $\begin{array}{l}\text { Resisted right twist, } 30 \% \\
\text { Attempted left twist, } 50 \% \\
\text { Attempted left twist, } 100 \%\end{array}$ & & $\begin{array}{r}73(64) \\
61(44) \\
112(48)\end{array}$ & $\begin{array}{l}112(58) \\
113(58) \\
174(80)\end{array}$ & $\begin{array}{l}36(18) \\
34(14) \\
76(35)\end{array}$ & $\begin{array}{l}30(39) \\
28(18) \\
51(25)\end{array}$ \\
\hline $\begin{array}{l}\text { Resisted right bend, } 30 \% \\
\text { Attempted left bend, } 50 \% \\
\text { Attempted left bend, } 100 \%\end{array}$ & & $\begin{array}{l}16(6) \\
21(15) \\
61(37)\end{array}$ & $\begin{array}{l}16(16) \\
30(36) \\
56(55)\end{array}$ & $\begin{array}{l}14(13) \\
15(13) \\
27(44)\end{array}$ & $\begin{array}{l}12(4) \\
12(4) \\
16(14)\end{array}$ \\
\hline $\begin{array}{l}\text { Resisted flexion, } 30 \% \\
\text { Attempted extension, } 50 \% \\
\text { Attempted extension, } 100 \%\end{array}$ & & $\begin{array}{l}12(4) \\
13(2) \\
16(3)\end{array}$ & $\begin{array}{l}12(1) \\
13(5) \\
14(2)\end{array}$ & $\begin{array}{l}13(3) \\
14(2) \\
30(14)\end{array}$ & $\begin{array}{l}23(8) \\
22(6) \\
49(21)\end{array}$ \\
\hline $\begin{array}{l}\text { Resisted extension, } 30 \% \\
\text { Attempted flexion, } 50 \% \\
\text { Attempted flexion, } 100 \%\end{array}$ & & $\begin{array}{r}94(57) \\
97(46) \\
209(77)\end{array}$ & $\begin{array}{r}83(52) \\
86(48) \\
188(79)\end{array}$ & $\begin{array}{l}41(25) \\
42(24) \\
99(61)\end{array}$ & $\begin{array}{l}13(6) \\
13(4) \\
23(17)\end{array}$ \\
\hline
\end{tabular}

Standard deviations in parentheses.

the neck muscles at the $\mathrm{C} 4$ level reflected both the convenience of making myoelectric measurements there and the assumption that knowledge of muscle contraction forces at that level would protray well typical magnitudes of neck muscle forces in general. Subjects were placed in a supported sitting posture for the experimental measurements so that they needed to pay little attention to maintaining their trunks upright in performing the various tasks asked of them. Internal loads in structures inferior to the neck probably have little influence on neck loads, so this choice of posture seemed reasonable. Measurement of myoelectric activities with fine wire intramuscular electrodes would have been preferable, in some ways, to measurement with surface electrodes. However, it seemed unwarranted to subject the volunteers to the discomfort and risk associated with use of intramuscular elec- trodes without first carrying out a study using surface electrodes.

The maximum voluntary twisting strengths developed by the subjects may have been limited by inability of the head/helment interface to transmit large moments without slipping. For all six modes of exertion, mean female strengths tended to be $60 \%$ to $90 \%$ of mean male strengths. The mean product of the neck diameters in the males was approximately $55 \%$ greater than in the females, which probably accounts at least in part for this gender difference.

The neck muscle strengths in attempted flexion and extension found in the present study are roughly equivalent to those reported earlier by Foust et al. (5). If the neck muscle strengths measured in this study are compared with lumbar trunk muscle strengths in healthy males and females (12), 
TABLE 5. Calculated muscle contraction forces $(N)$ for maximum voluntary efforts

\begin{tabular}{|c|c|c|c|c|c|}
\hline Muscle equivalent & Relaxed & $\begin{array}{l}\text { Attempted } \\
\text { left twist }\end{array}$ & $\begin{array}{l}\text { Attempted } \\
\text { left bend }\end{array}$ & $\begin{array}{l}\text { Attempted } \\
\text { extension }\end{array}$ & $\begin{array}{l}\text { Attempted } \\
\text { flexion }\end{array}$ \\
\hline $\begin{array}{l}\text { L Platysma } \\
\text { R Platysma }\end{array}$ & & $23(8)$ & $19(11)$ & & $\begin{array}{l}19(14) \\
19(14)\end{array}$ \\
\hline $\begin{array}{l}\text { L Infrahyoid } \\
\text { R Infrahyoid }\end{array}$ & & $\begin{array}{l}72(25) \\
68(30)\end{array}$ & $\begin{array}{l}60(35) \\
41(45)\end{array}$ & & $\begin{array}{l}62(45) \\
62(45)\end{array}$ \\
\hline $\begin{array}{l}\text { L SCM } \\
\text { R SCM }\end{array}$ & & $170(58)$ & $\begin{array}{r}140(83) \\
68(47)\end{array}$ & & $\begin{array}{l}145(106) \\
145(106)\end{array}$ \\
\hline $\begin{array}{l}\text { L Longi } \\
\mathrm{R} \text { Longi }\end{array}$ & & $31(11)$ & $26(15)$ & & $\begin{array}{l}26(19) \\
26(19)\end{array}$ \\
\hline $\begin{array}{l}\text { L Scal. ant. } \\
\text { R Scal. ant. }\end{array}$ & & $42(15)$ & $35(20)$ & & $\begin{array}{l}36(27) \\
36(27)\end{array}$ \\
\hline $\begin{array}{l}\text { L Scal. med. } \\
\text { R Scal. med. }\end{array}$ & $\begin{array}{l}3(1) \\
3(1)\end{array}$ & $45(15)$ & $37(22)$ & $\begin{array}{l}39(17) \\
39(17)\end{array}$ & \\
\hline $\begin{array}{l}\text { L Long. cerv. } \\
\mathrm{R} \text { Long. cerv. }\end{array}$ & $\begin{array}{l}2(1) \\
2(1)\end{array}$ & $29(10)$ & $24(14)$ & $\begin{array}{l}26(11) \\
26(11)\end{array}$ & \\
\hline $\begin{array}{l}\text { L Levator scap. } \\
\text { R Levator scap. }\end{array}$ & $\begin{array}{l}8(4) \\
8(4)\end{array}$ & $\begin{array}{l}2(3) \\
14(14)\end{array}$ & $106(62)$ & $\begin{array}{l}116(51) \\
116(51)\end{array}$ & \\
\hline $\begin{array}{l}\text { L Multifidus } \\
\text { R Multifidus }\end{array}$ & $\begin{array}{l}3(1) \\
3(1)\end{array}$ & $47(16)$ & $39(23)$ & $\begin{array}{l}42(19) \\
42(19)\end{array}$ & \\
\hline $\begin{array}{l}\text { L Semispin. cerv. } \\
\text { R Semispin. cerv. }\end{array}$ & $\begin{array}{l}7(3) \\
7(3)\end{array}$ & & $2(8)$ & $\begin{array}{l}96(42) \\
96(42)\end{array}$ & \\
\hline $\begin{array}{l}\text { L Semispin. cap. } \\
\text { R Semispin. cap. }\end{array}$ & $\begin{array}{l}9(4) \\
9(4)\end{array}$ & $96(22)$ & $111(57)$ & $\begin{array}{l}127(56) \\
127(56)\end{array}$ & \\
\hline $\begin{array}{l}\text { L Splenius cerv. } \\
\text { R Splenius cerv. }\end{array}$ & $\begin{array}{l}1(1) \\
1(1)\end{array}$ & $17(6)$ & $14(8)$ & $\begin{array}{l}15(7) \\
15(7)\end{array}$ & \\
\hline $\begin{array}{l}\text { L Splenius cap. } \\
\text { R Splenius cap. }\end{array}$ & $\begin{array}{l}4(2) \\
4(2)\end{array}$ & $68(23)$ & $56(33)$ & $\begin{array}{l}61(27) \\
61(27)\end{array}$ & \\
\hline $\begin{array}{l}\text { L Trapezius } \\
\text { R Trapezius }\end{array}$ & $\begin{array}{l}5(2) \\
5(2)\end{array}$ & $81(29)$ & $5(9)$ & $\begin{array}{l}73(32) \\
73(32)\end{array}$ & \\
\hline
\end{tabular}

Standard deviation are in parentheses.

$\mathbf{L}$, left; $\mathbf{R}$, right.

the moments exerted about L5 are an order of magnitude larger than those exerted about $\mathrm{C} 4$. This must be due in part to the larger cross-sectional areas and moment arms of the muscles of the lumbar region. Mean intraindividual ratios of strengths in maximum attempted extension to maximum attempted flexion for the neck muscles in

TABLE 6. Mean predicted motion segment reactions in maximal exertions

\begin{tabular}{lccc}
\hline Exercise & $\begin{array}{c}\text { Lateral } \\
\text { shear } \\
(\mathrm{N})\end{array}$ & $\begin{array}{c}\text { Anteroposterior } \\
\text { shear } \\
(\mathrm{N})\end{array}$ & $\begin{array}{c}\text { Compression } \\
(\mathrm{N})\end{array}$ \\
\hline Relaxed & $0(0)$ & $-2(1)$ & $122(36)$ \\
Left twist & $33(8)$ & $70(24)$ & $778(228)$ \\
Extension & $0(0)$ & $135(69)$ & $1164(494)$ \\
Flexion & $0(0)$ & $31(63)$ & $558(375)$ \\
Left bending & $125(58)$ & $93(59)$ & $758(422)$ \\
\hline
\end{tabular}

Standard deviations in parentheses. both males and females were approximately twice those found for the low back (12).

The coefficients of linear correlation between model predicted forces and measured myoelectric activities were weaker than those found earlier for the lumbar trunk. There are a number of reasons why this might have occurred. First, the assump-

TABLE 7. Coefficients of correlation of predicted muscle forces with measured myoelectric signals

\begin{tabular}{|c|c|c|c|}
\hline $\begin{array}{l}\text { Muscle } \\
\text { equivalent }\end{array}$ & $\begin{array}{l}\text { Paired } \\
\text { electrode }\end{array}$ & Left & Right \\
\hline Platysma & Anterior & 0.60 & 0.68 \\
\hline Infrahyoids & Anterior & 0.83 & 0.83 \\
\hline SCM & Anterolateral & 0.82 & 0.85 \\
\hline Scalene ant. & Posterolateral & 0.77 & 0.73 \\
\hline Levator scap. & Posterolateral & 0.33 & 0.29 \\
\hline Splenius cap. & Posterior & 0.60 & 0.75 \\
\hline Trapezius & Posterior & 0.49 & 0.41 \\
\hline
\end{tabular}


tion in the regressions of linearity between contraction force magnitude and myoelectric signal level probably is valid only approximately. Nonlinear regressions were not examined since evidence from earlier studies of lumbar trunk muscles suggests that significant nonlinearity seldom arises in force/ activity relations of the kind studied here $(17,18)$. Second, the model assumption that antagonistic cocontractions of muscles are minimal was clearly violated at least sometimes, which can be seen from the Table 4 myoelectric signal data. The assumption was used because it has proven reasonable in at least some similar circumstances $(17,18)$, and validated models incorporating more realistic assumptions in this regard have yet to be established. Third, and probably most important, myoelectric activities were measured by surface electrodes, and so could be affected by crosstalk among signals from different muscles. This may explain in part why the correlation coefficients for the more anterior muscles were better than for the more posterior muscles; there are only a few anterior muscles, but many posterior ones. Fourth, while the biomechanical model makes no distinctions about the mechanical functions of different muscles, they actually may be functionally differentiated. The weakest correlations were for the levator scapulae and trapezius muscles. These muscles may have primary functions other than to development moments about the cervical vertebrae. The correlation coefficients for the other muscles ranged from 0.60 to 0.85 , suggesting that the model used in these studies had a reasonable degree of validity. Further research can guide the development of cervical muscle action models with improved validity. Nevertheless, this first model of the quasistatic biomechanics of the neck muscles seems to be able to predict contraction forces adequately, at least in a semiquantitative sense.

Acknowledgment: The support of a Research Fellowship Grant from the Foundation for Chiropractic Education and Research and of Public Health Service Grants NS 20536 and $\mathrm{OH} 01962$ for this research, as well as the assistance of Karol Haderspeck-Grib, Alan Insley, Susan Lantz, Kathleen Reilly, John Triano, David Warwick, and Ed Zawacki, are gratefully acknowledged.

\section{REFERENCES}

1. Andersson GBJ, Ortengren R, Schultz AB: Analysis and measurement of loads on the lumbar spine during work at a table. J Biomech 13:513-520, 1980

2. Bean JC, Chaffin DB, Schultz AB: Biomechanical model calculation of muscle contraction forces: a double linear programming method. J Biomech 21:59-66, 1988

3. Clauser CE, McConville JT, Young JW: Weight, volume, and center of mass of segments of the human body. AMRLTR-69-70, Wright-Patterson Air Force Base, Ohio, 1969

4. Eycleshymer AC, Schoemaker DM: A cross-section anatomy, Appleton-Century-Crofts, New York, 1911

5. Foust DR, Chaffin DB, Snyder RG, Baum JK: Cervical range of motion and dynamic response and strength of cervical muscles. Proceedings of the 17th Stapp Car Crash Conference, Society of Automotive Engineers, 1973, pp 205-308

6. Horal $\mathrm{J}$ : The clinical appearance of low-back disorders in the city of Gothenburg, Sweden. Acta Orthop Scand suppl 118:1-109, 1969

7. Huelke DF, Nusholtz GS: Cervical spine biomechanics: a review of the literature. $J$ Orthop Res 4:232-245, 1986

8. Hult L: The Munkfors investigation. Acta Orthop Scand suppl 16:1-76, 1954

9. Hult L: Cervical, dorsal and lumbar spinal syndromes. Acta Orthop Scand suppl 17:1-101, 1954

10. Kelsey JL, Githens PB, Walter SD, et al: An epidemiological study of acute prolapsed cervical intervertebral disc. $J$ Bone Joint Surg 66A:907-913, 1984

11. McElhaney J, Roberts V, Paver J, Maxwell M: Etiology of trauma to the cervical spine. In: Impact injury of the head and spine, ed by CL Weing et al. C. C. Thomas, Springfield, IL, 1983

12. McNeill T, Warwick D, Andersson GBJ, Schultz AB: Trunk strengths in attempted flexion, extension, and lateral bending in healthy subjects and patients with low-back disorders. Spine 5:529-538, 1980

13. Moroney SP: Mechanical properties and muscle force analyses of the lower cervical spine, Ph.D. Thesis, University of Illinois at Chicago, 1984

14. Moroney SP, Schultz AB, Miller JAA, Andersson GBJ: Load-displacement properties of lower cervical spine motion segments. $J$ Biomech (in press)

15. Sances A, Myklebust JB, Maiman DJ, Larson SJ, Cusick JF, Jodat RW: The biomechanics of spinal injuries. CRC Crit Rev Biomed Eng 11:1-76, 1984

16. Schultz AB, Andersson GBJ: Analysis of loads on the lumbar spine. Spine 6:76-82, 1981

17. Schultz AB, Andersson GBJ, Ortengren R, Haderspeck K, Nachemson A: Loads on the lumbar spine. J Bone Joint Surg 64A:713-720, 1982

18. Schultz AB, Haderspeck K, Warwick D, Portillo D: Use of lumbar trunk muscles in isometric performance of mechanically complex standing tasks. J Orthop Res 1:77-91, 1983 